\title{
ТРАНСФОРМАЦИЯ МИРОВЫХ ЭНЕРГЕТИЧЕСКИХ РЫНКОВ: «УМНЫЙ ЭНЕРГЕТИЧЕСКИЙ РЫНОК SMART GRID»
}

\author{
(C) 2020 Гилязов Тимур Рустемович \\ E-mail:7402640@mail.ru
}

Рассматривается переход энергетического сектора к «умному энергетическому рынку». Анализируются перспективы и сформулированы цели развития мировых энергетического рынков.

Ключевые слова: энергетический рынок, экономическое развитие.

В современной мировой экономике эффективность использования энергоресурсов, а также их доступность, описывает состояние и уровень развития энергетического рынка. Резкие скачки цен на углеводородные ресурсы заставляют задумываться о разработке новых технологий, отказе от применения традиционных видов ресурсов. Однако, существуют периоды падения цен, которые мы переживаем в наши дни и не можем начать развитие новых проектов. При всем этом большое количество факторов, воздействующих на энергетический рынок, перспективы самого рынка и спекулятивное поведение игроков рынка являются причиной отсутствия равновесия цен на энергоресурсы.

Рынок энергоресурсов является лишь частью глобального экономического рынка, несмотря на влияние на мировой рынок и колоссальные денежные обороты. Все участники энергетического рынка - от нефтяного сектора до инновационных ресурсов - постоянно пытаются повысить собственную эффективность, а также борются с непрекращающейся конкуренцией. Данную конкуренцию определяют и окружающее информационное поле, и фундаментальные факторы. Иногда общественное внимание, которое может быть обращено к разным ситуациям на рынке, может перерастать в глобальную проблему. Такие действия приводят к переделу сложившейся информационной карты и средств. Хорошим примером могут послужить техногенные и природные катастрофы, которые оказывают сильное давление на атомную отрасль. Другой пример - это возобновляемые источники энергии. Рынок пытается сделать шаги к предотвращению глобального потепления и придает всеобщее значение альтернативным источникам энергии.

На сегодняшний день существует ряд прогнозов будущего мирового энергетического рынка, которые оказывают большое влияние на энергетическую безопасность страны. Огромный рынок услуг по формированию прогнозов был образован из-за этой потребности. Существует ряд известных организаций, которые предоставляют такие прогнозы: Международный институт прикладного системного анализа (IIASA), Международное энергетическое агентство (МЭА), Управление энергетической информацией администрации США (EIA) и другие. Кроме этого, прогнозы по спросу и предложению, объемам добычи и уровню цен на энергетические ресурсы публикуются крупнейшими компаниями в этой отрасли: ЛУКОЙЛ, ГАЗПРОМ, ConocoPhillips, BР, российскими ИНЭИ РАН, Институтом энергетической стратегии и другими известными организациями. Существует ряд проблем, связанных с точностью прогнозов и оценок, на которые влияют следующие причины:

1) большой массив прошлых прогнозов, который нужно вписать в текущую экономическую конъюнктуру;

2) следование заранее определенному экономическому и политическому курсу;

3) отношение организации к определенному кругу лиц, теории;

4) борьба за власть и сферы влияний.

Перечень трудностей, связанных с российским энергетическим сектором, был выявлен много лет назад. Со временем уровень проблем меняется, но пути их решения до сих пор не идеальны. Значение рынка энергетики для экономики России слишком высокое, а пути решения ограничены. К сожалению, государственные задачи сводятся больше к конъюнктурным, тактическим целям, а не стратегическим. И даже эти стратегические пути решения могут быть упущены из виду, оставаясь тезисами на бумаге, и не иметь ничего общего с реальной государ- 
ственной политикой.

Постепенно воздействуя на факторы, сдерживающие развитие «чистых технологий», трансформируя энергетическую систему, расширяя границы использования возобновляемых энергоресурсов в наиболее востребованных географических и технологических зонах, правительство способно создать институциональные условия для развития под отрасли альтернативной энергетики, в рамках, целесообразных для энергетической отрасли в целом. Мы согласны с мнением Рязановой Г.Н. [11], что институциональные условия, воздействующие на развитие возобновляемой энергетики, включают в себя три ключевых сегмента:

- связанные с правовыми основами технологического характера, ответственность за экологические правонарушения и др.);

- несущие экономический характер (сфера налогообложения, субсидирования и другие способы экономической мотивации хозяйствующих субъектов);

- формирующие организационный механизм (пропаганда «чистой энергетики», построение организационно-экономических единиц в рамках каждого экономического агента данного рынка на всех иерархических уровнях) [11].

Одна из главных задач развития энергетического рынка России - внедрение инновационных энергетических технологий, обеспечение их конкурентоспособности по отношению к возобновляемым ресурсам и неопределенность выбора. Все это ведет к рискам деградации экономического развития и падения спроса на экспорт российских ресурсов. Именно тема «Умного энергетического рынка» может стать ответом на решение данного вопроса. Термоядерная, водородная энергия, нетрадиционные углеводороды и возобновляемые источники энергии всех видов занимают в этой теме особое место. «Умный энергетический рынок» модернизирует существующие методы использования и получения всех видов энергии и энергетических ресурсов, создание информационных систем нового поколения, инновационные способы связи и транспорта. Развитие и модернизация новых технологических процессов направлены на повешение уровня энергоэффективности, использование «умных технологий», внедрение комплексной переработки энергетических ресурсов, исследование многокомпонентных месторождений сырья и внедрение новых типов ВИЭ и других энергетических ресурсов. Одним из самых важных компонентов развития информационных систем в энергетике на сегодняшний день является концепция Smart Grid. Планируется рассмотрение и принятие нескольких важных законодательных актов в России. Инфраструктура энергетического сектора в России сегодня очень изношена, поэтому концепция Smart Grid очень актуальна. Согласно данной концепции можно выделить ряд ключевых задач развития ИТ инфраструктуры в энергетическом секторе:

1) активное тестирование и использование на точках измерения инновационных измерительных приборов «умных» (smart)счетчиков использования ресурсов. Данные счетчики оборудованы дистанционными датчиками управления, измеряемыми преобразователями и линией протоколов, которые отвечают регламентам информационной безопасности;

2) использование на всех объектах, которые имеют отношение к электрическим ресурсам (жилые здания, коммерческие помещения, заводы и др.) АИИС - усовершенствованных автоматизированных измерительных систем, которые снимают показания и ведут измерения в режиме реального времени. Такие приборы ведут мониторинг процессов, контролируют качество энергии, режим теплоснабжения, а также выполняют задачи автоматического регулирования обмена с внешним миром;

3) разработка сети коммуникаций на базе различных линий связи - ВОЛС, ЛЭП связь, волновые и спутниковые виды. Каждая отдельная АИИС должна иметь связь по двум и более видам каналов связи;

4) использование компаниями автоматизированных систем АС управления, мониторинга и регулирования производственной деятельности.

Smart Grid («интеллектуальные сети электроснабжения») - это сети нового поколения, использующие сети коммуникаций, собирающие всю информацию об энергопотреблении. Сети позволяют в автоматическом режиме повысить надежность, эффективность производства и устойчивость распределения энергии. Система Smart Grid разделяется на несколько ключевых звеньев4:

1) приборы измерения, которые имеют smart-датчики и счетчики;

2) инновайионные методы управления;

3) иннновационные составляющие элек- 
трической сети: сверхустойчивые кабели, накопители, гибкие системы FACTS;

4) переработанные технологии по мониторингу и контролю управления спросом на энергоресурсы, интерфейс по принятию ключевых решений, системы автоматического измерения процессов и текущего контроля за генерацией.

Мы разделяем мнение Кондракова О.В. [6], что концепция Smart Grid подразумевает:

- развитие инновационных энергосберегающих технологий;

- производство высокоинтеллектуальной продукции,

- применение электричества на транспорте,

- привлечение потребителей в качестве участников рынка [6].

Интеллектуальная сеть, по мнению Кондракова О.В. [6], полностью автоматизирована и обеспечивает параллельный поток от генерирующих источников до потребителя электричества и информации о параметрах и характеристиках сети. Мы разделяем его мнение, что применение энергоэффективных передовых технологий позволяет добиться следующих преимуществ:

a) экономические - снижается себестоимость продукции из-за издержек производства, рационально используются ТЭР, сокращается срок окупаемости инвестиций;

б) технологические - повышается экономичность работы оборудования, эффективно используются производственные мощности, по- вышается надежность и безопасность, снижается энергоёмкость производства;

в) экологические - снижается количество выбросов загрязняющих веществ в тропосферу и загрязнённых стоков в гидросферу, продукция получается экологически чистой;

г) социальная - повышается безопасность труда и улучшаются условия труда [6].

Сегодня на рынке мировой энергетики наблюдается процесс глобализации технологий, которая ведет к росту конкуренции и новых технологий, увеличение глобального трансферта. Такой процесс обеспечивает и приводит к переходу на новый энергетический уклад на рынке. Смысл нового уклада заключается в изменении энергетических ресурсов и перехода к энергетическим технологиям и услугам. Главным триггером роста мировой экономики становятся инновации и технологии, которые приводят к быстрому развитию материального производства и инновационного комплекса. Однако, многие технологии нового уклада должны адаптироваться к составу природных ресурсов и новым способам их комплексной добычи. Энергия становится все доступнее с каждым новым десятилетием. Все новые территории покрываются доступом к энергоресурсам, увеличивается автономное использование оборудований путем использования аккумуляторной энергии. Расширяются зоны географических поставок энергии. Это происходит за счёт подключения новых

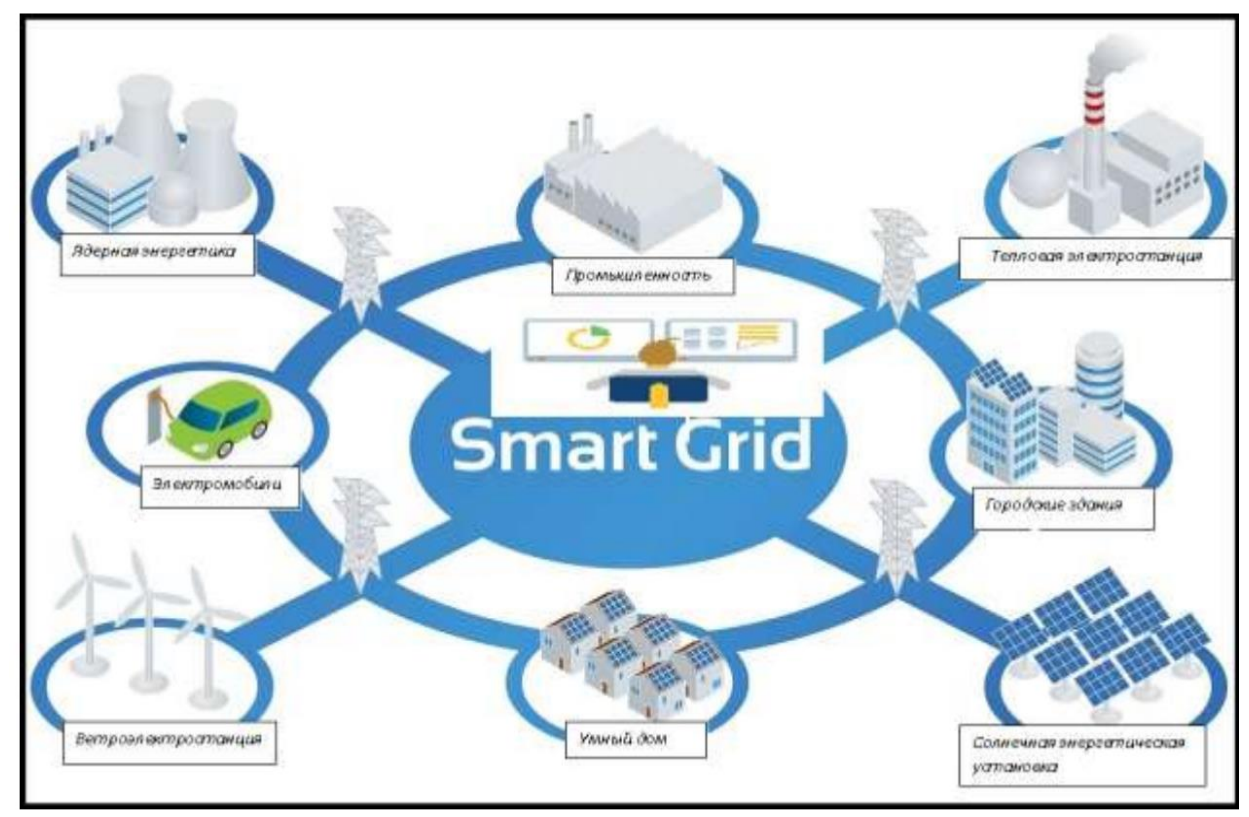

Рuc. 1. Концепция «Smart grid» 
территорий к сетям электроэнергии, развитию инфраструктуры. Популярными становятся предложения замкнутого энергоснабжения труднодоступных территорий без подключения к существующим энергосистемам. Это значит, что в ближайшем будущем возможно появление территорий с местной эффективной энергосистемой.

С другой стороны, огромную роль в становлении «умного энергетического рынка» играют корпорации и большие компании. Такие компании формируют устойчивую модель спроса на технологии. В свою очередь, этот спрос влияет на крупные мировые компании. Компании, оказывающие услуги в этой сфере, производители оборудования и другие оказываются в этом поле влияния. Они становятся лидерами производственных изменений, основанных на потенциале кадров, инвестиционном ресурсе и стратегическом векторе. Все это ведет к «зеленой экономике» и инновациям неиндустриального развития. Отношения между странами энергетического рынка могут изменится в ходе технологический глобализации. Многие страны уже формируют энергетическую самодостаточность - эта тенденция становится все более наблюдаемой. Они используют технологические успехи и опыт для повышения энергетической безопасности страны. Страны - импортеры энергии уходят от сокращения собственных до- быч и увеличивают импорт к максимальному энергообеспечению собственными ресурсами. Например, США придерживается энергетической стратегии, согласно которой их энергетика перейдет на полностью самообеспеченный региональный рынок энергетики к 2030 году.

Основными видами ресурсов самообеспеченного рынка энергетики будут нетрадиционные виды (сланцевый газ, тяжелая нефть, шахтный метан). Также будет использоваться потенциал ВИЭ. ЕС также стремится сформировать общий энергетический рынок и инфраструктуру на базе Северной Африки, Норвегии и территории ЕС. Главная задача - достичь максимального уровня ресурсного самообеспечения на базе нетрадиционных видов ресурсов и ВИЭ. Китай тоже создает развитый рынок энергетики на базе собственного потенциала, отказываясь от зависимости от импорта, а также развивает зону влияния в области энергетики в регионах Дальнего Востока, Юго-Восточной Азии и Центральной Азии. Как следствие, все это может сказаться и на российском экспорте углеводородов в страны, которые стремятся к энергетической самодостаточности. Ориентиром должен послужить тот факт, что в странах ОЭСР потребление сокращается, в то время как развивающимися странами Африки, Азии будет обеспечен основной прирост энергопотребления.

\section{Библиографический список}

1. Распоряжение Правительства Российской Федерации от 13 ноября 2009 г. № 1715-р Энергетическая стратегия России на период до 2030 года // Министерство энергетики Российской Федерации.

2. Амелин, А. Экономика и ТЭК сегодня /А. Амелин // Энергоэффективность и энергоснабжение.- 2013.№ 11 .

3. Жуйков Е.Н. Современные направления развития энергетического комплекса российской федерации // Фундаментальные исследования. - 2007.- № 12-2.- С. 312-313.

4. Интеллектуальные сети Smart Grid - будущее российской энергетики//Режим доступа http://www.sicon.ru/ about/articles/?base=\&news=16 свободный (дата обращения 12.09.2020)

5. Козловский, E.M. ТЭК: сущность, проблемы, перспективы/ Е. М. Козловский - М: Линк, 2017. - 340 с.

6. Кондраков О.В. Повышение энергетической безопасности на основе экономически устойчивого развития топливно-энергетического комплекса// диссертация ... доктора экономических наук: 08.00.05/ Тамбов.2019. - 359 с. Режим доступа https://swsu.ru/upload/iblock/ff4/kondrakovov_dissertatsiya.pdf свободный (дата обращения 11.10.2020).

7. оростышевская Е.М., Миэринь Л.А., Фахрутдинова Е.В. Инновационная система ЕС и место России в европейском инновационном пространстве// Современное искусство экономики. - 2015. - № 2 (20). - С. 59 -67.

8. Михайлов С., Экономика и ТЭК сегодня / С. Михайлов // Возобновляемая энергетика сегодня и завтра.2013. № 11.- С. 9-10.

9. Накоряков, В.Е. Воспроизводство минерально-сырьевой базы и инвестиции - основные проблемы топливно-энергетического комплекса.-М: Наука, 2012.-198 с.

10. Присецкий Е.Л. Введение в экономическую географию и региональную экономику России. М. - 2008. - 549 c. 
11. Рязанова Г.Н. Институциональные аспекты альтернативного энергообеспечения предприятий в народном хозяйстве// диссертация ... кандидата экономических наук: 08.00.05/ Москва.- 2015.-208с. Режим доступа http://www.cemi.rssi.ru/dissertation/defense/ryazanova/diss_ryazanovoy.pdf свободный (дата образения 12.09.2020).

12. Фахрутдинова E.В., РоднянскийД.В. Анализ энергетических кластеров и их влияния на социальноэкономическое развитие регионов России// Экономические науки.-2016. - № 142.- С. 26-29.

13. Fakhrutdinova E., Kirshin I., Kolesnikova J., Salyakhov E. THE INFLUENCE OF CROSS-COUNTRY TECHNOLOGICAL TRANSFER ON ECONOMIC PROFIT FORMATION// Middle East Journal of Scientific Research. 2013. T. 17. № 12. C. 1632-1634. 